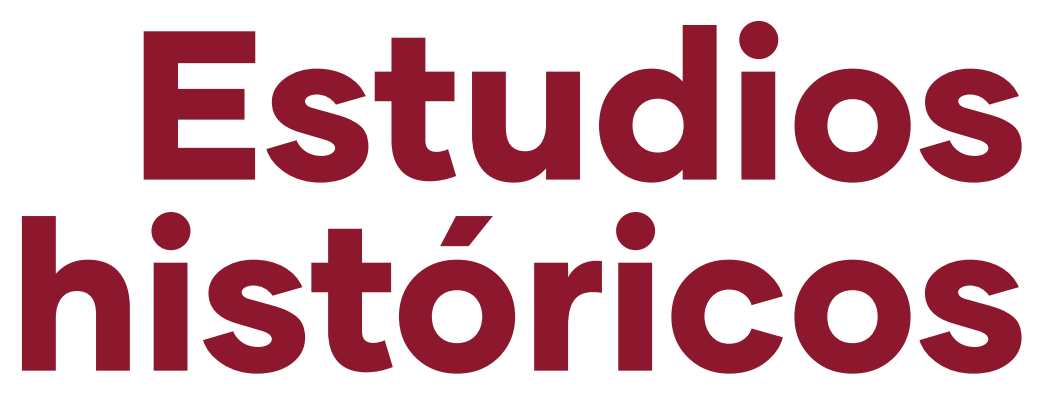

\title{
Santa Librada, de los partos difíciles a la Independencia de Cundinamarca
}

\section{Saint Librada, from the difficult births to the Independence of Cundinamarca}

Recibido: 15 de febrero de 2020

Aceptado: 15 de marzo de 2021

DOI: $10.22517 / 25392662.23521$

pp. 1-25

\author{
Abel Fernando Martinez Martin ${ }^{1}$ \\ abelfmartinez@gmail.com \\ https://orcid.org/0000-0002-4621-6072
}

\section{Andres Ricardo Otalora Cascante ${ }^{2}$}

arotalorac@unal.edu.co

https://orcid.org/0000-0002-0793-4602
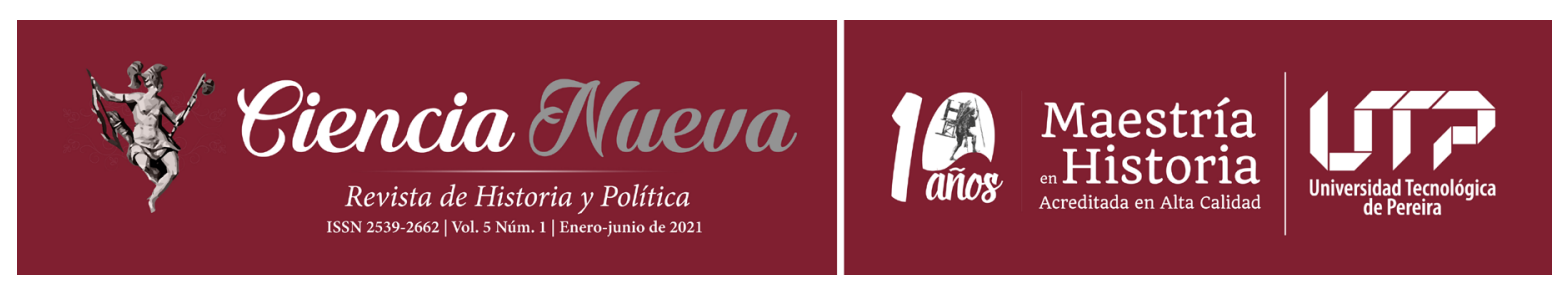

1 Doctor y Magister en Historia de la Universidad Pedagógica y Tecnológica de Colombia en Tunja, doctor en Medicina y Cirugía de la Universidad Nacional de Colombia en Bogotá. Profesor Asociado de la Escuela de Medicina, Facultad de Ciencias de la Salud de la Universidad Pedagógica y Tecnológica de Colombia UPTC en Tunja, Colombia. Director del Grupo de Investigación Historia de la Salud en Boyacá -UPTC y del Museo de Historia de la Medicina y la Salud-UPTC en Tunja. 2 Doctor en Historia y Magister en Antropología de la Universidad Nacional de Colombia en Bogotá. Investigador del Grupo de Historia de la Salud en Boyacá-UPTC de la Universidad Pedagógica y Tecnológica de Colombia en Tunja. Actualmente trabaja en la Universidad Nacional de Colombia, Sede Bogotá.

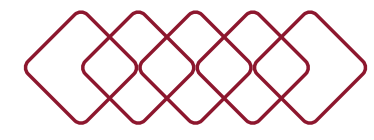


Resumen

Este artículo aborda la leyenda y la historia de santa Librada y su relación taumatúrgica con los partos difíciles, la esterilidad y los problemas conyugales; la introducción de su culto por el obispo-virrey Ladrón de Guevara en el siglo XVIII en Panamá, Quito y Lima y su llegada al convento-hospital de San Juan de Dios de Santafé. La relación de la fiesta de la santa con el día de la Independencia originó una particular simbiosis de este símbolo, primero taumatúrgico y luego político, que hizo parte de la fiesta nacional de Colombia hasta los años sesenta del siglo XX.

Palabras clave: santa Librada, religiosidad, historia de la salud, Independencia, fiesta nacional, Bogotá.

\section{Abstract}

This article refers to the legend and history of Saint Librada and its thaumaturgical relationship with difficult births, sterility, and marriage problems; the introduction of her cult by the Bishop-Viceroy Ladrón de Guevara in the 18th century in Panama, Quito and Lima and its arrival at the convent-hospital of San Juan de Dios in Santafé. The relationship between the celebration day of saint Librada with the Independence Day of Colombia gave rise to a political symbol, which was part of the national holyday of Colombia until the sixties in 20th century.

Keywords: Saint Librada, religiosity, health history, Independence, national holyday, Bogotá.

\section{Introducción}

La desaparición de los símbolos de la monarquía hispánica, producto de la declaración de Independencia de la primera república neogranadina que se dio en Santafé, a principios del siglo XIX, generó un gran vacío simbólico en una monarquía que se caracterizó por la representación de los símbolos de la Iglesia y la corona durante casi trescientos años. El altar y el trono, asociados desde la conquista, se transformaron en el altar y la república que los nuevos gobernantes criollos y las autoridades eclesiásticas, que simpatizaban con la Independencia, empezaron a resignificar. La construcción de estas comunidades nacionales tuvo que recurrir a símbolos genealógicos que dotaran de legitimidad a los nuevos regímenes políticos y a sus ejércitos ante el embate no solo de los realistas, sino de las soberanías provinciales que se alzaban contra los tradicionales centros de poder y proponían regímenes políticos diferentes.

El caso de santa Librada, patrona de los partos difíciles y las dificultades conyugales de las mujeres, fue producto de la situación descrita. La imagen de la santa Virgen y mártir, que perteneció a la iglesia del convento hospital de San Juan de Dios de Santafé, imagen escultórica destinada por su donante para auxiliar a las embarazadas en los partos difíciles, de pronto se vio elevada a la condición de patrona de la independencia de Cundinamarca; es decir, la santa patrona del centralismo, debido a una coincidencia: su fiesta se celebraba cada año el 20 de julio.

El 20 de julio se celebra aún en Colombia como un día festivo, con banderas, desfile 
militar y discurso en el Capitolio Nacional. Se conmemora la fecha de la instauración de una Junta de Gobierno en Santafé en 1810 y la firma de un Acta de Independencia, que se refiere a Fernando VII, como el "amado monarca», quien había sido apresado dos años antes por Napoleón. Esta misma figura la usaron muchos cabildos urbanos a lo largo de la monarquía, durante la ocupación del ejército francés a la península. Desde la instauración de las celebraciones patrias a finales del siglo xIx y la aparición de las academias de historia nacional y regionales a inicios del $\mathrm{xx}$, el día 20 de julio ha sido una de las fechas clásicas de la historia académica colombiana.

La particular historia del martirio de esta santa ibérica sirvió pedagógicamente para explicar el movimiento de separación de la metrópoli, y fue usada por los partidarios de Antonio Nariño y del centralismo para exaltar los valores del precursor presidente. Una santa joven, virgen y mártir que compartió el destino del joven héroe y protomártir neogranadino Antonio Ricaurte, cuya primera representación en referencia a su heroico sacrificio en la hacienda de San Mateo se escenificó precisamente en la fiesta de Santa Librada y de la Independencia, el 20 de julio de 1815.

Santa Librada, ligada en sus inicios a la protección de las parturientas y las dificultades matrimoniales, quedó ligada con la fecha clásica de la Independencia Nacional y estaba en los desfiles de la fiesta patria con sus variaciones, dependiendo del partido gobernante. Apareció hasta los años 60 del siglo xx cuando quedó recluida en el Museo Casa del Florero, erigido por la Academia Colombiana de Historia para conmemorar el sesquicentenario de los hechos ocurridos en Santafé de Bogotá, el 20 de julio de 1810.

\section{La leyenda de la santa, virgen y mártir Librada}

De acuerdo con el Breve resumen de las glorias de la Virgen y Mártir Santa Librada, patrona de la Santa Iglesia Catedral de Sigüenza y su obispado ${ }^{1}$, obra publicada en la ciudad española de Murcia en 1732, Librada nació en el año 119 de nuestra era en una ciudad de Galicia, cuando Hispania era una provincia del Imperio romano. Su madre, Calcia, dio a luz en un parto múltiple a nueve criaturas, todas ellas niñas. Lo que vio como peligroso la madre, pensando que pudiera granjearle serios problemas con su esposo Lucio Catelio, por entonces, pretor romano de los territorios de Galicia y Lusitania, y quien durante el embarazo de su mujer fue trasladado a la ciudad de Tarragona, en el Mediterráneo, dejando a Calcia en Galicia, al noreste de Hispania.

El parto múltiple era considerado por los romanceros medievales como un verdadero oprobio, como una monstruosidad, «pues no es de maravillar que una mujer preñada de simiente de varón pariese tanta generación». Los autores clásicos comparan a la mujer multípara con la animalidad y con las bestias: «Lo cual, aún a los puercos o a otras animalias es cosa

1 Joseph Cayuelas Díaz, Breve resumen de las glorias de la Virgen y Mártir Santa Librada, patrona de la Santa Iglesia Catedral de Sigüenza y su obispado con el modo de hacer su Novena, para alcanzar del Señor, por intersección de la Santa, las gracias que se desean (Murcia: por Joseph Díaz Cayuelas, impresor de la ciudad, en frente de San Francisco, 1732).

\section{Estudios Históricos}


monstruosa $»^{2}$, el exceso de fertilidad era relacionado no solo con la animalidad, sino con la infidelidad. Siguiendo al filósofo griego Aristóteles, el útero tenía siete supuestas subdivisiones anatómicas en las paredes, por tanto, solo podía albergar a siete criaturas en su interior. Por eso el exagerado número de nueve hermanas mellizas era considerado como un suceso antinatural, anormal, condenable, pecaminoso, excesivo y monstruoso ${ }^{3}$.

Fue así como Calcia, la multípara mujer del pretor romano le entregó las nueve niñas a Sila, doncella que la había asistido en el parto múltiple, para que las arrojara inmediatamente al río Miño y se ahogaran las nonillizas ${ }^{4}$, ocultando así a los ojos de su distante marido el parto múltiple y solucionando el problema mediante el infanticidio, que no era una práctica extraña en la época romana ${ }^{5}$.

Sila, la doncella, quien luego sería mártir de la Iglesia, profesaba el cristianismo, por lo que se abstuvo de cumplir con la orden dada por la desnaturalizada madre, a quien se le acusa en las historias de la vida de santa Librada...

de tener menos sensibilidad que los animales: que la loba, la osa, la tigre o la leona, todos animales salvajes que $[. .$.$] «amando tanto a sus hijos, si ven venir a los cazadores, por guardarles, mil veces ponen$ por ellos las vidas por defenderlos. Y esta mujer se puede llamar más fiera que todos estos animales, persiguiendo a su misma generación, porque se trabaja en matarla» ${ }^{6}$.

La cristiana Sila bautizó a las nueve hijas en las aguas del Miño, donde las niñas estaban condenadas a morir ahogadas, ocultándolas posteriormente en el arrabal de la ciudad gallega de Bayona de $\mathrm{Tuy}^{7}$, donde residía un importante grupo de cristianos primitivos, que habían sido convertidos tras las enseñanzas del apóstol Santiago en las tierras del noroccidente de Hispania ${ }^{8}$.

Entradas en plena juventud, las nueve mujeres fueron bautizadas y nombradas Librada, Genoveva, Gema o Marina, Victoria, Eumelia, Germana, Marciana, Basilisa y Quiteria ${ }^{9}$. Criadas por Sila, fueron puestas bajo la protección del obispo de Braga, san Ovidio, quien las reunió en una comunidad femenina. Las nueve hermanas tomaron el voto de castidad y permanecían enclaustradas en constante oración. La belleza física de las nueve jóvenes se identifica en la leyenda con la belleza de su espíritu, opuesta a la horrible fealdad de los que las martirizarían.

Por orden de Roma llegaron envidados del emperador a Galicia, con la orden de iniciar la persecución de la secta de los cristianos y extinguir sus prácticas religiosas. Siendo notables las virtudes y gracias que tenían las nueve doncellas cristianas, los enviados del em-

2 María Eugenia Díaz Tena, «La vida de Santa Librada y su fuente medieval», Culturas Populares n. 8 (2009): 9.

3 Jacques Gélis, «Le cuite de Santa Librada a Sigüenza: Patronage urbain et emblématique impériale», Revista de Dialectología y Tradiciones Populares 51, n. ${ }^{\circ} 1$ (1996): 223.

4 Díaz, Breve resumen de las glorias..., 8.

5 Diaz Tena, «La vida de Santa Librada y su fuente medieval», 10-11.

6 Diaz Tena, «La vida de Santa Librada y su fuente medieval», 10.

7 La leyenda varía dependiendo de la fuente, en algunos textos franceses de la región de Aquitania, Calcia era reina de Lusitania (Portugal) y sus nueve hijas princesas. Gélis, «Le cuite de Santa Librada...», 222.

8 Díaz, Breve resumen de las glorias..., 9.

9 La santa virgen y mártir Quiteria, hermana menor de Librada, también desempeña un papel taumatúrgico porque es invocada en el santoral como protectora de la rabia en la región de Aquitania.

Ciencia Nueva. Revista de Historia y Política | ISSN 2539-2662 | Vol. 5 Núm. 1 (enero-junio de 2021) DOI: https://doi.org/10.22517/25392662.23521 
perador romano apuntaron primero hacia ellas, ordenando su sacrificio al pretor encargado de aplicar justicia, sin saber este que estaba más comprometido en el problema de lo que creía, pues se trataba de sus propias hijas ${ }^{10}$.

Al llevarlas ante el pretor romano Lucio Catelio, las nueve doncellas se presentaron como esposas de Cristo y también como hijas del desconcertado pretor, quien sorprendido por la declaración de sus nueve hijas llamó inmediatamente a su esposa Calcia, quien le confirmó la noticia oculta de su múltiple paternidad. El padre abrazó a sus hijas y suspendió el acto de justicia romana.

Restituyéndolas en su tratamiento como hijas del pretor romano, este trató de convencerlas de abandonar el cristianismo y convertirse en vestales de la religión imperial, pero las nueve unánimemente se rehusaron. El pretor Lucio Catelio les ofreció entonces que se convirtieran en castas sacerdotisas de la diosa Diana ${ }^{11}$, ante lo cual Librada contestó que preferiría antes el martirio que renegar de la fe en Cristo. El padre desilusionado, ofendido y furioso las encerró en prisión ${ }^{12}$. Las mártires dispuestas al sacrificio decidieron escapar de la prisión, separarse y morir en manos de otros tiranos y no de su propio padre, deseo que se cumplió en distintos lugares de la península ibérica, el norte de África y el Medio Oriente.

La joven Librada se retiró a vivir con otros cristianos a un bosque ${ }^{13}$, donde los adoctrinó y allí fueron luego capturados todos por el tirano de Anphiloquia (Ourense), quien la sometió a tortura para hacerla renegar de su fe ${ }^{14}$. Tras fracasar, el tirano la condenó a ser crucificada (figura 1) y Librada, con 20 años, se regocijó de morir en la cruz como Cristo, yendo rápida a cumplir su martirio, mientras seguía predicando, siendo la primera mujer en ser crucificada ${ }^{15}$. Tras padecer los más brutales tormentos, la mártir cristiana fue crucificada en Castelo Branco, en la provincia de Lusitania, actual Portugal, en el año 139.

Su cuerpo se conserva en la catedral de Sigüenza donde tiene una capilla ${ }^{16}$, allí fue llevado en el siglo xiı por el monje benedictino Bernardo de Agén, quien las trasladó desde Sainte Livrade sur Lot en la antigua Aquitania ${ }^{17}$. Bernardo participó en la reconquista de Sigüenza de manos de los moros ${ }^{18}$ y fue el primer obispo de la ciudad reconquistada. La fiesta primitiva de santa Librada, tanto en Aquitania como en Sigüenza, se celebraba el 18 de enero, pero en 1537, con motivo del traslado de sus restos a su nueva capilla, la fiesta se trasladó al

10 Díaz, Breve resumen de las glorias..., 11.

11 Díaz, Breve resumen de las glorias..., 13.

12 Diaz Tena, «La vida de Santa Librada y su fuente medieval», 11.

13 Diaz Tena, «La vida de Santa Librada y su fuente medieval», 12.

14 Díaz, Breve resumen de las glorias..., 14.

15 Díaz, Breve resumen de las glorias..., 17.

16 Díaz, Breve resumen de las glorias..., 18.

17 Juan A. Martínez Gómez-Gordo, «Santa Librada, virgen y mártir (revisión de su hagiografía, iconografía y culto)», Anales Seguntinos n. ${ }^{\circ} 12$ (1996): 15.

18 El plateresco altar en la capilla de la antigua patrona de la catedral de Sigüenza del siglo xvi contiene la imagen de Librada sobre un trono de justicia y escenas de la crucifixión, de la vida de las nueve hermanas y de los trabajos de Hércules, héroe mitológico que hizo parte del discurso iconográfico de la monarquía desde Carlos v. Gélis, «Le cuite de Santa Librada a Sigüenza: Patronage urbain et emblématique impériale», 226, 233-234.

\section{Estudios Históricos}


20 de julio ${ }^{19}$.

Parte de los poderes taumatúrgicos atribuidos a la santa se deben a que fue un benedictino quien llevó a Sigüenza sus restos. La orden fue creada por san Benito de Nursia, noble italiano que, en el año 543, fundó la orden Benedictina en el monasterio de Monte Casino cerca de Nápoles sobre las ruinas de un antiguo templo de Apolo. Contaba con biblioteca, hospital y escuela y fue la cuna de la medicina monástica que desarrolló Europa Occidental.

La regla benedictina es la primera en dedicarse plenamente al cuidado de los enfermos: "Ante todo y sobre todo ha de cuidarse de los enfermos, de modo que se les sirva como a Cristo en persona, pues él mismo dijo: "Estuve enfermo, y me visitasteis", y: "Lo que hicisteis a uno de estos más pequeños, a mí lo hicisteis $»^{20}$. Los monasterios benedictinos tenían enfermerías que se terminaron convirtiendo en hospitales donde se enseñaba la medicina como parte de la física. Estos primeros hospitales, del latín hospedar, poco a poco se fueron convirtiendo de sitios de hospedaje de peregrinos en sitios de atención de enfermos, pobres de solemnidad, leprosos, ancianos, lisiados y no faltaron los locos, en el contexto de las reformadas misericordia y caridad cristianas.

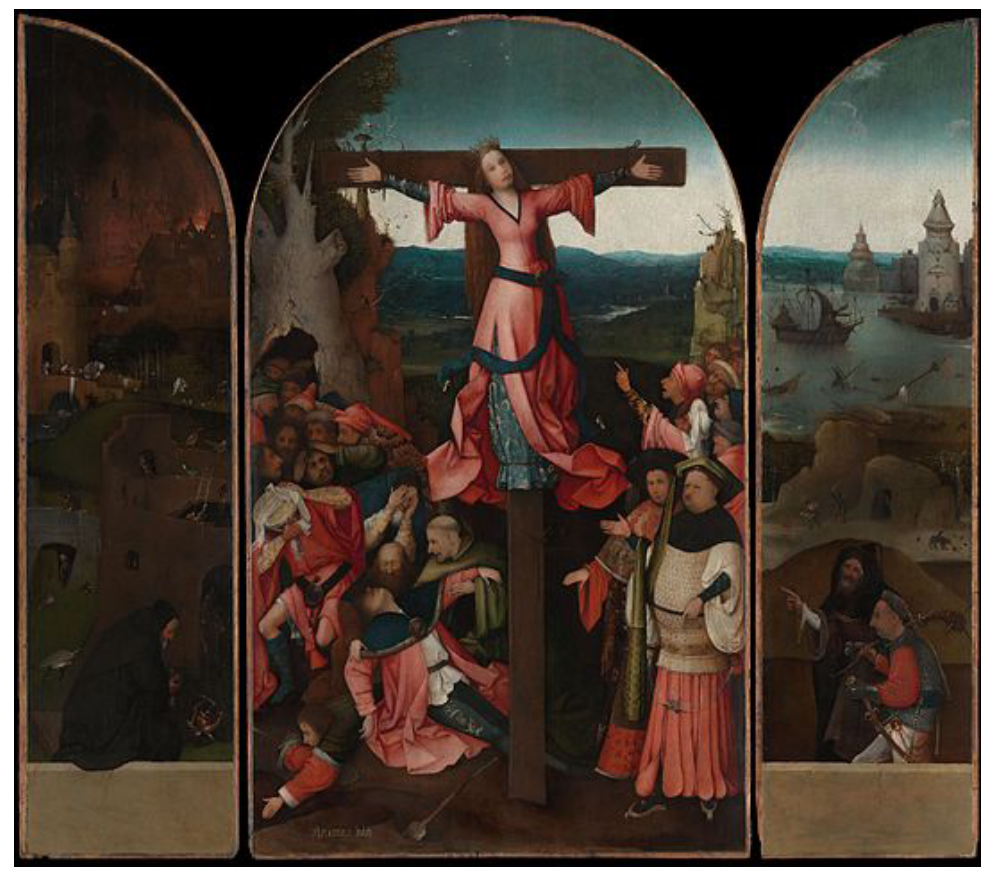

Figura 1. Hieronymus Bosch (El Bosco), La Santa Crucificada, tríptico ca. 1500-1504.

Fuente: Palacio Ducal de Venecia (Italia).

19 En Balcalgia, Baiona la Real, villa marinera gallega testigo de la llegada de la carabela La Pinta el 1 de marzo de 1493 portando la noticia de lo que después se llamaría el descubrimiento de América, se ordenó en 1688 la celebración de la fiesta el 20 de julio. En 1689, la catedral de Sigüenza envío un hueso de uno de los brazos de la santa engastado en un relicario de plata. En 1701 se terminó la barroca capilla en su honor. Martínez Gómez-Gordo, «Santa Librada...», 16, 26.

20 Benito de Nursia, Regla de nuestro padre San Benito (Madrid: Biblioteca de Autores Cristianos, 2000), 76. 
No solo en la Edad Media se tuvo a santa Librada como patrona de las parturientas de riesgo y los problemas en el matrimonio. Ya en el siglo XIX, en 1826, el propio rey Fernando viI estuvo en la ciudad castellana de Sigüenza para visitar la urna que contiene las reliquias de santa Librada, que fue abierta para que la joven reina María Josefa Amalia de Sajonia, su tercera esposa, le pidiera la gracia a la santa ante la presencia de su reliquia de engendrar un heredero varón, pues la pareja real no había logrado tener descendencia tras siete años de matrimonio ${ }^{21}$.

Las reliquias de santa Librada, que a lo largo de los siglos se han repartido desde Sigüenza ${ }^{22}$, fueron parte de un culto medieval muy extendido hacia los restos de los protomártires y vírgenes, que vendría a ser regulado por el Concilio de Trento (1545-1563). Las reliquias fueron una de las formas de relación más próximas de los creyentes con lo sagrado, los cuerpos martirizados de los protomártires cumplieron funciones taumatúrgicas para los enfermos y eran eficientes intermediarios ante la divinidad para obtener el perdón de sus pecados y la curación de sus males ${ }^{23}$.

\section{La leyenda de la santa, virgen y mártir barbada Wilgerfortis}

A santa Librada se le suele confundir con Wilgerfortis (virgen fuerte), virgen con barba que fue crucificada al igual que la santa virgen Librada, y que su culto aparece en el norte de Francia, Alemania y algunos países de la cuenca del Rin. Pocas historias de santas tienen tantos elementos fantásticos y difíciles de corroborar como el mismo nombre de la protagonista. Dignefortis, Wilgerfortis, santa Liberata, santa de la Barba, santa Barbuda, Komina, Uncumber, Ulfe, Europia, etc. Pero en algo parece coincidir el culto a santa Wilgerfortis y es que ella es la santa patrona de aquellas mujeres obligadas a aceptar un matrimonio, unión o compromiso no deseado. Ella logró heroicamente resistir a la imposición de un matrimonio y dio testimonio con su vida.

La confusión se le atribuye al jesuita Jerónimo Ramón Higuera (1538-1611) quien inventó un Cronicón perdido, el cual atribuyó al escritor ibérico Flavio Lucio Dextro (¿? -444) y en el cual se hacia una apología a la monarquía, donde además une las dos historias de las vírgenes mártires medievales europeas ${ }^{24}$.

Una de las historias de Wilgerfortis proviene de la Edad Media y la ubica como hija del rey de Portugal. Su extraordinaria belleza y su condición noble la habrían hecho objeto de molestos pretendientes aspirantes a casarse con ella. Siendo una niña casi adolescente, Wilgerfortis no tenía intención alguna de casarse con nadie, llevaba una vida austera y religiosa ${ }^{25}$.

21 Marcos Nieto Jiménez, Santa Librada. Lo que se esconde detrás (Guadalajara, España: Aventura Gráfica, 2017), 198.

22 Martínez Gómez-Gordo, «Santa Librada...», 50.

23 Jacques Gélis, «Reliquias y cuerpos miraculados», en Historia del Cuerpo vol. I., coord. por Alain Corbin, Jean Jacques Courtine y Georges Vigarello (Madrid: Taurus, 2005), 86.

24 Adrián Contreras, «In Ligno Facta. Artes escultóricas de los siglos xvir y xviII en Colombia» (tesis doctoral, Universidad de Granada, Doctorado en Historia y Artes, Departamento de Historia del Arte, 2017), 194. No fue esta la única polémica sobre la hagiografía de Santa Librada que se atribuye al Cronicón. Ver: Martínez Gómez-Gordo, «Santa Librada...», 31.

25 Luis Salvador López Herrero, «Anorexia: comer nada. Una perspectiva psicoanalítica», Revista de la Asociación Española de Neuropsiquiatría XIX, n. 72 (1999): 599.

\section{Estudios Históricos}


Pero un día el padre hizo un acuerdo con el rey de Sicilia, un hombre anciano para la época de alrededor de 50 años y le envía un retrato de su hija ${ }^{26}$. Este rey al contemplar la belleza de Wilgerfortis acepta inmediatamente el matrimonio propuesto. Cuando la noticia llega a la corte de Portugal, el padre la recibe como un excelente acuerdo político y su hija, como una verdadera sentencia de muerte, pues no había posibilidad alguna de resistirse o negarse al mandato del padre.

Continúa la leyenda, Wilgerfortis en una tensa espera se niega a comer y consagra todas sus energías a la oración, pidiéndole a Dios que la libere de su belleza que tanto pesar y dolor le estaba causando ${ }^{27}$. La joven pidió a Dios que la despojase de sus atributos de belleza femenina, que la convirtiese en un ser repulsivo y así poder desanimar a su pretendiente para poder mantenerse virgen. El milagro sucedió, su cuerpo femenino se virilizó, le creció una espesa barba, se llenó de vello, se agravó su voz y su cuerpo se masculinizó; santa Wilgerfortis murió martirizada en la cruz.

Cuando el rey de Sicilia, que en unas versiones era un musulmán, finalmente llega a Portugal y conoce a la joven prometida a quien le había crecido de esa manera el vello facial, se marcha ofuscado y se niega a casarse con una mujer barbada. El padre encolerizado ante su fracaso político la encierra primero, la acusa de herejía y la sentencia a morir, el culto cristiano la evoca y la representa como una santa crucificada, con rasgos viriles a causa de su barba ${ }^{28}$.

El culto a santa Wilgerfortis se extiende durante el siglo xv por el centro y el este de Europa, santa de las malcasadas cuya protección invocan las mujeres con maridos violentos y alcohólicos, llegando en sus distintas versiones también a América, incluido el Nuevo Reino de Granada, pero con la versión de santa Librada, santa crucificada, pero sin la barba de Wilgerfortis, quien no protege a las parturientas, sino que representa el valor de la mujer que prefiere perder la vida antes que renunciar a decidir qué hacer con ella (figura 2).

La Iglesia retiró del santoral a santa Librada y a Wilgefortis por no existir evidencias documentales de su existencia real, al igual que a San Jorge y a San Cristóbal en 1962. La devoción por la virgen mártir santa Librada estaba más acentuada en el sur de Europa, en las islas Canarias y en América, donde se le tuvo por abogada de los partos difíciles, santa patrona de las mujeres estériles, protectora de las madres multíparas, pero también se la tenía a la santa mártir crucificada, como abogada del corazón alegre ${ }^{29}$. Preadolescente y hermosa, santa Librada se invocaba para librarse de maridos que dan mala vida al ser maltratadores o

26 Margarita E. Gentile, "Ciento nueve años después de "La Cruz en América”", en Los crucificados, religiosidad, cofradías y arte, ed. por Francisco Javier Campos y Fernández de Sevilla (San Lorenzo del Escorial: Real Centro Universitario Escorial-María Cristina, 2010), 1008.

27 Eulàlia Carrascal Corbera, «Apologia de l’anorèxia i la bulímia. Treball d’investigació sobre la cara més desconeguda d'una patología endémica» (tesis de grado en Periodismo, Universidad Autónoma de Barcelona, 2018), 12.

28 Jacobo Sanz Hermida, «UUna vieja barbuda que se dice Celestina”: Notas acerca de la primera caracterización de Celestina», Celestinesca 18 (1994): 22.

29 Joaquín Fernández García, Rodrigo Fernández Alonso y José Martínez González, «Oraciones para la salud humana y animal en la poesía popular asturiana», en Actes del is Conceyu Internacional de Lliteratura Asturiana, ed. por Academia de la Llingua Asturiana (Oviedo: Academia de la Llingua Asturiana, 2007), 131. 
borrachos y también en el frecuente caso de los matrimonios no deseados ${ }^{30}$. En Argentina se describe todavía esta breve oración para casos de emergencia relacionados con el parto o los fugitivos: «Santa Librada, Santa Librada, líbranos de esta disparada» ${ }^{31}$.

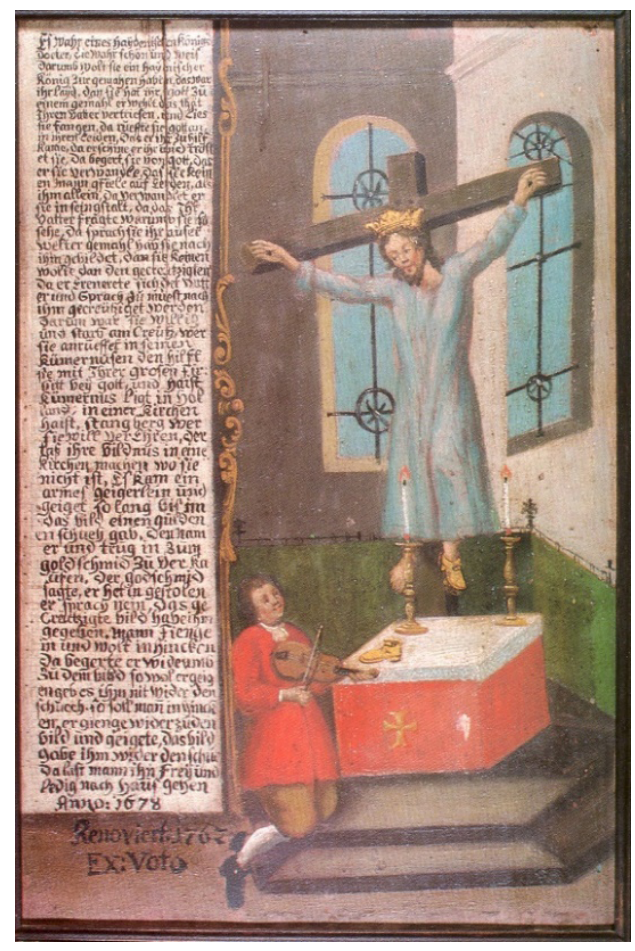

Figura 2. Anónimo, Miniatura de santa Wilgerfortis o Kummernis, 1678, Städtisches Museum. Uno de los milagros más conocidos que se le atribuyen a la barbuda virgen centroeuropea es el de la leyenda del violinista pobre, quien, condenado a muerte por robo, pidió tocar frente a una imagen de la santa que le arrojó una bota de oro con lo cual evitó su castigo.

Fuente: Peter Spranger, Der Geiger von Gmünd: Justinus Kerner und die Geschichte einer Legende (Heidelberg: Stadtarchiv, 1991), 25.

\section{El obispo-virrey Ladrón de Guevara y la tardía devoción de santa Librada en la Amé- rica hispánica}

Don Diego Ladrón de Guevara Orozco y Calderón, nacido en 1641 en la villa de Cifuentes, en Guadalajara, realizó estudios en la Universidad de Alcalá de Henares y se graduó como doctor en Derecho. Se desempeñó como gobernador del obispado de Almería, consiguió una canonjía en Sigüenza, lugar donde se familiariza. Pasó a América como obispo de Panamá en 1689, ciudad en la que ocupa interinamente el cargo de capitán general de Tierra Firme y presidente de la Audiencia, luego pasa a Guamanga en el alto Perú en $1695^{32}$, para

30 Anónimo, Novena a la gloriosa virgen y mártir Santa Librada o Wilge-Forte, abogada de quitar los pensamientos tristes, y afligidos. Patrona de la Santa Catedral de la ciudad de Sigüenza, y su Obispado (Córdoba: en la oficina de Don Juan Rodríguez de la Torre, Calle de la Librería, 1785).

31 Gentile, «Ciento nueve años después de "La Cruz en América», 1007.

32 En su corto gobierno organizó la Universidad de San Cristóbal y fundó un convento de Carmelitas Descalzas.

\section{Estudios Históricos}


más tarde ocupar la Diócesis de Quito en 1704 como su decimotercer titular. En junio de 1710 se trasladó a Lima, donde ocupó hasta 1716 el cargo de virrey del Perú. En 1718 le fue aceptada su renuncia al arzobispado limeño, año en que muere en la ciudad de México, es enterrado en su catedral metropolitana ${ }^{33}$.

A parte de sus múltiples obras al frente del gobierno eclesiástico y civil en Panamá, Guamanga, Quito y Lima, el obispo-virrey Ladrón de Guevara se caracterizó por tener una gran devoción hacia santa Librada desde su época en Sigüenza, donde la virgen mártir era patrona de la diócesis ${ }^{34}$. Desde América, el obispo-virrey envió grandes sumas de dinero para la celebración de la fiesta de la santa en Sigüenza ${ }^{35}$.

El obispo de Quito y virrey del Perú Ladrón de Guevara va dejando testimonios de su devoción por santa Librada en su recorrido americano por las ciudades de Panamá ${ }^{36}$, Quito ${ }^{37}$ y Lima ${ }^{38}$. Contribuyó a la difusión de esta devoción con imágenes escultóricas, como la talla policromada quiteña de ojos de vidrio y máscara metálica ${ }^{39}$, enviada para la nueva iglesia del convento hospital de San Juan de Dios de Santafé, que se inauguró en $1723^{40}$ (figura 3).

En la iglesia del convento hospital de Jesús, María y Señor San José de esta corte, la santa, acogida por los hospitalarios santafereños, que no es raro que adopten a varios santos que son proveedores de salud, continuó con su patrocinio a las mujeres embarazadas, estériles o con otras dificultades en el matrimonio y con su colaboración en los partos difíciles, propiedad que le atribuyeron desde el siglo XII, coincidiendo con la llegada de sus restos a la

33 Ángel Justo Estebaranz, «Las donaciones a España del obispo de Quito don Diego Ladrón de Guevara», Artigrama n. ${ }^{\circ}$ 24 (2009): 226-227.

34 Gélis, «Le cuite de Santa Librada a Sigüenza: Patronage urbain et emblématique impériale», 228.

35 Estebaranz, «Las donaciones a España del obispo de Quito don Diego Ladrón de Guevara», 232.

36 El obispo Ladrón de Guevara reconstruyó la catedral de la ciudad y la fortaleza en la desembocadura del río Chagres.

37 Actualmente, una escultura de Santa Librada de gran tamaño puede verse hacia la mitad de la nave en la iglesia del monasterio de la Concepción en Quito. Como obispo de Quito, Ladrón de Guevara realizó la entrega del hospital real de la Misericordia de Nuestro Señor Jesucristo a los betlemitas, trabajó además en las reparaciones de la catedral y la construcción del sagrario. A sus expensas mandó erigir un altar en honor a Santa Liberata. José María Vargas, Historia de la Iglesia en el Ecuador durante el patronato español (Quito: Editorial Santo Domingo, 1962), 339. La orden hospitalaria de Nuestra Señora de Belén fue creada por religiosos franciscanos en la ciudad de Guatemala en 1650. Fue aprobada por bulas de 1672 y 1674 y en 1697, Inocencio xi la transformó en orden religiosa bajo la regla de San Agustín con voto de hospitalidad. Los primeros betlemitas llegaron a Quito en 1702 provenientes de Lima. En 1705 la Real Audiencia solicitó el paso del hospital real de la Misericordia de Quito de la cofradía del mismo nombre a los betlemitas. El acto de entrega del local y la iglesia antigua se verificó a inicios de 1706 y fueron los betlemitas los responsables del culto a San Juan de Dios en Quito. Tuvieron hospitales en las ciudades de México, Puebla, La Habana, Lima, Cusco y Potosí, entre otras. Jorge Moreno Egas y Nancy Morán Proaño, Historia del antiguo Hospital San Juan de Dios Tomo I (Quito: Museo de la Ciudad, 2012), 92-93.

38 La iglesia de Santa Liberata en la alameda de Lima data del año 1711, bajo el gobierno eclesiástico y civil del obispo Ladrón de Guevara, ayudado por los betlemitas. El obispo se desempeñó además activamente en las obras de la catedral de Lima e igualmente creó en 1711 las cátedras de Medicina y de Anatomía en la Real Universidad de San Marcos. Pedro de Peralta Barnuevo y Rocha, Imagen política del gobierno del Excmo Señor [sic] D. Diego Ladrón de Guevara, Obispo de Quito, Virrey ... de los Reynos del Perú, Tierra firme y Chile (Lima: por Jerónimo de Contreras, 1714), 16-17, 74.

39 La ficha de la escultura en la colección del Museo de la Independencia-Casa del Florero, administrado por el Ministerio de Cultura establece que se trata de una talla de la escuela quiteña (ca 1750) de 118 x 74 x 32 cm, (realizada en madera, pigmentos, metal y vidrio).

40 Jaime de Almeida. «Um lugar de memória e de esquecimento: Santa Librada, padroeira da Independência da Colômbia», Revista Brasileira de História 31, n. ${ }^{\circ} 61$ (2011): 43-44. 
ciudad de Sigüenza ${ }^{41}$.

La escultura de santa Librada tiene como características un buen manejo de la talla, una refinada técnica pictórica, se le colocaron ojos de vidrio y tiene una máscara metálica en la cara y es atribuida a la escuela quiteña del siglo XVIII.

En 1726, la santa ya se encuentra en el inventario levantado en la nueva iglesia del convento-hospital santafereño ${ }^{42}$. En otro de los múltiples inventarios hospitalarios, levantado esta vez por fray José de Alvarado prior de dicho convento por orden del vicario provincial hospitalario fray Antonio de Guzmán, el 2 de octubre de 1756, se puede ubicar la santa dentro de la iglesia en la denominada nave de san Cayetano, Librada aparecen en el ítem 40:

En la nave el altar de nuestro señor San Miguel. En donde está la efigie del santo de bulto, en el nicho de en medio con velo de persiana, y gotera de madera, y en los nichos de los lados las efigies de bulto de santa Liberata y santa Rita con un crucifijo en la mano, y en el remate una efigie de pincel de Nuestra Señora, tiene este altar frontal y colaterales de bermellón y oro y es todo dorado ${ }^{43}$.

\section{Santa Librada, patrona de la independencia de Cundinamarca}

La figura de la virgen mártir, cuya fiesta en el santoral católico coincidía con la proclamación de la Junta en Santafé, el 20 de julio de $1810^{44}$, fue empleada por Antonio Nariño como presidente de Cundinamarca y sus partidarios a partir de 1812, año en el que se inauguró la fiesta y la procesión en honor a la santa de la Independencia, con la imagen escultórica policromada que se encontraba en la iglesia del convento hospital de San Juan de Dios. Nariño, por la traducción de los Derechos del Hombre, había sido acusado por los españoles de ateo y jacobino.

La singular historia de santa Librada, aparte de su evidente símil fonético, es vista como símbolo de la Independencia en razón a los detalles de su vida y martirio. La Nueva Granada — santa Librada - y las provincias americanas — sus ocho hermanas - abandonadas primero por su madre - la monarquía hispánica - y luego encarcelada, desterrada y amenazada de muerte por su padre peninsular - Fernando viI-, a quien resisten y desafían, aun-

41 En el texto museográfico de Almeida y Gamboa, se refieren a que la imagen de santa Librada llegó al Museo del 20 de julio, posterior a 1957, ya encontrándose en la Casa en 1960. Mencionan los investigadores que se produjo otro traslado anterior del hospital a la vecina iglesia de Santa Inés luego de su demolición para ampliar la carrera $10^{\circ}$. Jaime de Almeida y William Gamboa ¡Santa Libertad! Memoria y olvido de una imagen femenina de la Independencia (Bogotá. Ministerio de Cultura, Museo de la Independencia-Casa del Florero, Sociedad de Mejoras y Ornato de Bogotá, 2009). Sin embargo, de acuerdo con Duque Gómez, en 1955 Santa Librada aún permanecía en la sacristía de la iglesia de San Juan de Dios. Rodolfo Vallín y Laura Vargas Murcia, Iglesia de San Juan de Dios (Bogotá: Arquidiócesis de Bogotá. 2004), 58. La iglesia de Santa Inés cerró sus puertas a finales de 1956 y fue demolida en 1957, en el claustro anexo funcionó la Facultad de Ciencias Naturales y Medicina de la Universidad Nacional entre 1876 y 1916.

42 Vallín y Vargas, Iglesia de San Juan..., 79.

43 Vallín y Vargas, Iglesia de San Juan..., 203.

44 Ver: Armando Martínez Garnica, «La reasunción de la soberanía por las juntas de notables en el Nuevo Reino de Granada», en 1808. la eclosión juntera en el mundo hispano, coord. por Manuel Chust (México: Fondo de Cultura Económica, El Colegio de México, 2007), 286-333. Javier Ocampo López, El proceso ideológico de la emancipación en Colombia (Bogotá: Planeta, 1999), 319-331.

\section{Estudios Históricos}


que en ello se les vaya la vida - la guerra de Independencia-.

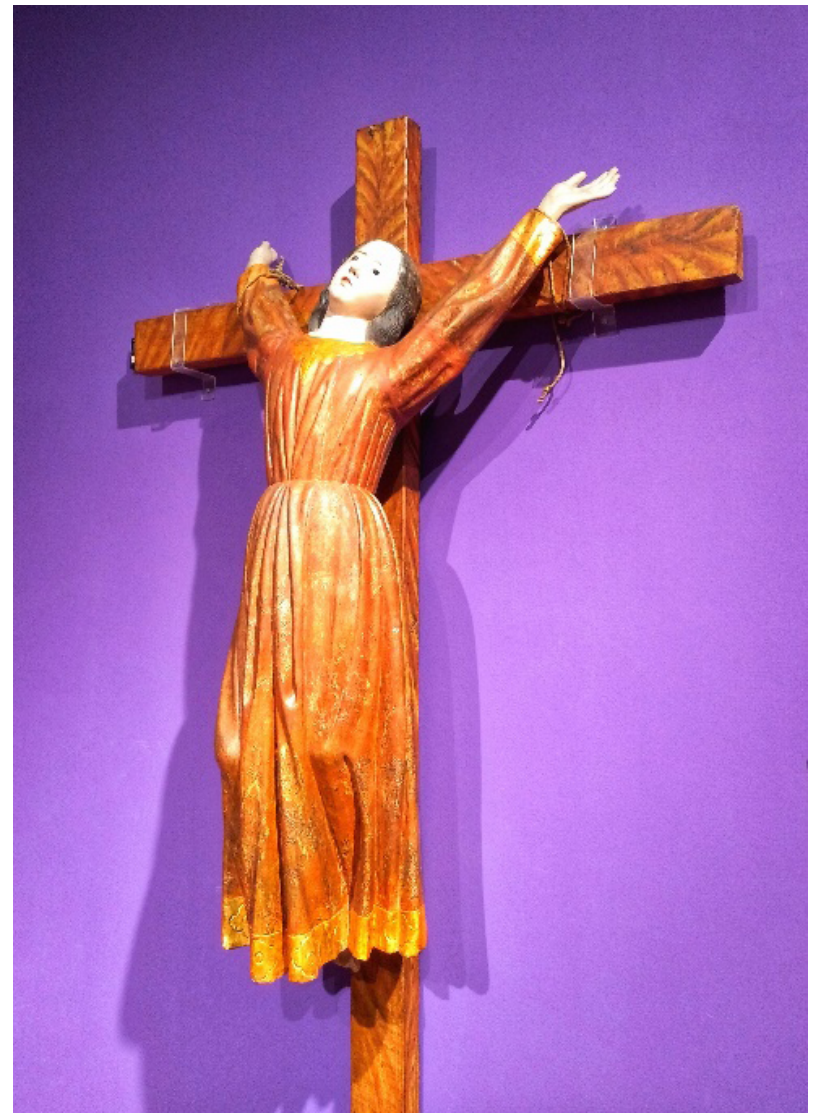

Figura 3. Santa Librada. Escuela Quiteña (ca 1720), talla en madera policromada.

Fuente: Colección del Museo de la Independencia - Casa del Florero, Ministerio de Cultura, Bogotá (Colombia).

La ruptura de los símbolos monárquicos y del régimen político permite la resignificación de Librada, discípula de Santiago Matamoros y virgen de la reconquista de Sigüenza, relacionada en esta diócesis con Hércules y Carlos v a partir del Renacimiento, que es convertida en símbolo de la Libertad y la independencia de Cundinamarca y en instrumento de legitimidad política del régimen centralista frente a los poderes emergentes de las Provincias Unidas de Nueva Granada. El vínculo con el trono se había roto, no obstante, el vínculo con el altar se mantenía y se empleó con éxito en la figura del primer símbolo patrio de la Independencia de la Nueva Granada.

Pocos meses después de ser ratificado como presidente de Cundinamarca por el Colegio Electoral y en los primeros días de 1812, Antonio Nariño fue homenajeado por el cabildo de la capital, antes de partir a la Campaña del Sur. El sermón que se hizo para elogiarlo estaba dedicado a santa Librada como patrona de Cundinamarca y, por primera vez, se empleó el nombre indígena de la capital, Bogotá. El sermón fue pronunciado por el payanés fray Francisco Florido de la orden de San Francisco, se imprimió a costa del cabildo. El padre Florido 
fue capellán castrense en la campaña que hizo Nariño contra Tunja y luego lo acompañó en la Campaña del Sur. Tras la batalla de la Cuchilla del Tambo, fue aprisionado, enviado a Santafé y condenado al destierro ${ }^{45}$.

Este discurso intenta unir el concepto de Madre Patria con Cundinamarca a través del designio divino de la Independencia por la intersección de la virgen y mártir santa Librada que ha dispuesto: «Se elija un presidente digno del Estado para la felicidad de Cundinamarca» ${ }^{46}$. El padre Florido propone el plan de su discurso, que se vería realizado en las fiestas que en honor a la patrona del Estado se celebrarían con gran boato en 1813 y 1815 :

Debemos a imitación del cabildo de esta villa alabar alegres al Todopoderoso, porque continuando sus beneficios para con nosotros por intersección de santa Librada (como piadosamente se cree) ha dispuesto se elija un presidente del Estado para el régimen y buen orden de la sociedad [...] En el deseo grande que me asiste de ver felices a los hijos y habitantes del Bogotá Granadino ${ }^{47}$.

En la catedral de la capital de Cundinamarca, donde se dieron cita el cabildo y las autoridades civiles y eclesiásticas, Florido hace alusión a la imagen de santa Librada transportada a la catedral desde la iglesia del convento hospital de San Juan de Dios:

Complace el Altísimo de que Cundinamarca se haya acogido bajo los auspicios de la gloriosa santa Librada, nos presentan en este Templo, su imagen, para que a su vista levantemos las manos al cielo y bendigamos a nuestro Dios, que quiere comencemos a gozar las felicidades todas de un gobierno acertado por la elección de nuestro Presidente ${ }^{48}$.

En la alabanza de la santa, Florido pone por ejemplo a Librada trayendo a colación la leyenda de esta virgen y mártir:

Dios que libró a Santa Librada de los furores de una madre cruel y de la sevicia de los verdugos, dispuso a esta virgen para que fuera el consuelo y la alegría de Cundinamarca, como el honor y gloria de Sigüenza ${ }^{49}$.

Finalmente dice:

Cuando al retiraros del trabajo, os dediquéis al recreo, contemplando en los frutos reproducida vuestra existencia, tomadlos en los brazos, y mostrándoles con paternal cariño, la imagen de Santa Librada, decidles con entusiasmo: Esta es, hijos míos, la imagen de aquella Santa, en cuyo día se tremolaron

45 Fray Francisco Florido, sacerdote franciscano payanés nacido en 1781. A fines de 1795 ingresó en la orden de San Francisco en el convento de Santafé, donde obtuvo grados de lector y presbítero. Se desempeñó como visitador del convento de Tunja en 1822, donde tuvo como secretario a fray José Antonio Chávez. Fue superior del convento de Bogotá. Acompañó a Nariño en la Campaña del Sur y fue capellán castrense en la campaña de Nariño contra Tunja. Luego de la batalla de la Cuchilla del Tambo, donde fue aprisionado, fue enviado a Bogotá, donde fue condenado a destierro, no obstante, se ubica en Ubaté hasta 1819. Cuando vuelve a Bogotá para obtener el curato de Moniquirá y luego el de Ramiriquí de 1820 a 1827 . En 1822 estuvo presente en la inauguración del Colegio de Boyacá en Tunja. Alfonso Zawadzky, «Fr. Francisco Antonio Florido», Repertorio Boyacense 7, n. 75 (1925): 85-90.

46 Real Academia de la Historia (RAH), Madrid: Signatura 9/7649 legajo 6 c) 1, folio 191-200. Francisco Florido, Sermón que en la fiesta de Santa Librada hecha en obsequio del Excmo. Señor Presidente Don Antonio Nariño por el ilustre cabildo de la villa de Bogotá, pronunció el padre Franciscano Florido de la Orden de San Francisco, el día 3 de enero de 1812 (Villa de Bogotá: Imprenta de D. Bruno Espinosa, 1812), 4.

47 Florido. Sermón que en la fiesta de Santa Librada..., 5.

48 Florido. Sermón que en la fiesta de Santa Librada..., 6.

49 Florido. Sermón que en la fiesta de Santa Librada..., 6.

\section{Estudios Históricos}


las banderas de la Libertad en el Cundinamarca dichoso. Esta es aquella santa por quien reasumimos nuestros derechos, sin que se hubiera experimentado ni la más leve desgracia: esta es aquella por la que salieron victoriosas las tropas cundinamarquesas en la Expedición del Sur: esta es aquella por quien nos hemos formado un Gobierno justo, un Gobierno liberal; y esta es aquella en cuya fiesta solemne se nos enseñaron por primera vez, los deberes del hombre para con su patria ${ }^{50}$.

El nombre de Librada se prestaba para muchas variaciones de la misma palabra: libertad, liberación, liberal, libre o liberada.

En 1813, con el fin de las guerras entre federalistas y centralistas, se celebró la fiesta de la Independencia, iniciando el domingo 18 de julio con un bando, lo que no fue obstáculo para que un mozo de ruana, como narra Caballero, partiera el árbol de la libertad y aparecieran por el barrio de santa Inés multitud de letreros denigrativos contra el presidente Nariño ${ }^{51}$. Al día siguiente, se formaron en la plaza las milicias y las calles se adornaron, plantándose otro árbol donde se había partido el anterior.

El gobierno y la representación nacional marcharon entonces a la iglesia del convento de los hospitalarios en la calle de San Miguel y en procesión llevaron la imagen de santa Librada hasta la Catedral, luego de lo cual hubo iluminación general. El martes 20 de julio, fiesta de la santa, se predicó en la Catedral, con discurso nuevamente del padre Florido, luego de lo cual se celebró un Te Deum, finalizando la fiesta con la jura de la Independencia por el presidente, las corporaciones, los prelados, eclesiásticos, colegios, síndico y cabildos en el palacio. El último acto de este simbólico día fue el de la bandera de las milicias patriotas, que Nariño ordenó traer a palacio y luego en presencia de todos le fueron cortadas las armas reales que tenía fijadas ${ }^{52}$.

En 1814 se verificó la misma fiesta, las tropas se formaron en la plaza y el presidente con la representación nacional fueron a la iglesia de San Juan de Dios trayendo a santa Librada hasta la Catedral. El día 20 se predicó la misa en presencia de la imagen sobre la transformación política sufrida el 20 de julio de $1810^{53}$.

\section{Jóvenes mártires. Santa Librada y Ricaurte}

El 16 de junio de 1814, un año antes, la Gazeta Ministerial de Cundinamarca publicaba un discurso de elogio y glorificación del mártir Antonio Ricaurte muerto en la hacienda de San Mateo en los valles de Aragua en la Capitanía General de Venezuela el 25 de marzo de 1814. En el discurso se señalaba cómo el héroe neogranadino había superado a los héroes clásicos, para del Molino, «esta laudatio a Ricaurte marca el inicio de la construcción de la heroicidad moderna neogranadina en cuanto que, por un lado, es la constatación del floreci-

50 Florido. Sermón que en la fiesta de Santa Librada..., 19.

51 José María Caballero, Particularidades de Santafé (Bogotá: Biblioteca Popular de Cultura Colombiana. Publicaciones del Ministerio de Educación de Colombia, 1946), 141.

52 Caballero, Particularidades..., 142.

53 Caballero, Particularidades..., 166. 
miento de la virtus republicana autóctona» ${ }^{54}$.

George Lomné reveló la importancia que el mito alrededor del sacrificio de Antonio Ricaurte empezó a tener en las fiestas en honor a la nación, a sus padres, héroes y mártires después del triunfo de Boyacá. Héroes que se convertirán en arquetipos de valores como la valentía, el caso de Ricaurte y el estoicismo, el caso de Policarpa Salavarrieta. El autor cita un homenaje a Bolívar hecho en la parroquia de San Pedro en Antioquia en 1829, en el que se exalta la virtud del mártir neogranadino en una representación efectuada con el mismo guion de la santafereña de 1815: «El pueblo inflamado del regocijo que podía concebir, creía ver reproducido el héroe bogotano que, de este modo tan honroso, salvó su Patria de los tiranos, eligiendo la muerte que ofreció en holocausto sobre las aras de la Independencia ${ }^{55}$.

Volviendo con santa Librada, en la fiesta del 20 de julio de 1815, Caballero narra:

\begin{abstract}
Se trajo de San Juan de Dios a santa Librada, con toda la ostentación posible; asistió el gobierno provincial; hubo refresco y baile en palacio, en celebración del aniversario de nuestra transformación política. Al baile asistieron 175 señoras, carracas, y adictas al gobierno y otros tantos hombres de la misma opinión. El 20 se celebró el tradicional Te Deum por la Independencia en la Catedral y la predicación en presencia de la imagen de santa Librada. El viernes 21, toros y, a la noche comedia con el mismo lujo, y aún más, porque la iluminación fue con esperma. Al principio se dio un monólogo por la niña hija del teniente-gobernador, el ciudadano Ignacio Vargas. Después siguió la comedia de Julio César y se concluyó con otro monólogo de Antonio Ricaurte, el que se sentó en un baúl de pólvora y le pegó fuego por no ser cogido por los godos, por el lado de Caracas, criollo de esta ciudad. ¡Admirable valor!, pero no para imitarlo ${ }^{56}$.
\end{abstract}

De acuerdo con Almeida, quien ha publicado varios artículos sobre el papel de santa Librada en la Independencia, ese mismo año, los hospitalarios publicaron la «Novena a la gloriosa virgen y mártir santa Librada, patrona, protectora y libertadora de los ciudadanos de la Nueva Granada», redactada por Miguel Antonio Escalante, presbítero de la orden de San Juan de $\operatorname{Dios}^{57}$.

Con la llegada del Ejercito Expedicionario de Costa Firme a Santafé el 6 de mayo de 1816, la llamada expedición de reconquista concluye el primer ciclo de fiestas dedicadas a santa Librada o al joven mártir Ricaurte en la Independencia Nacional. El 20 julio de ese año, Caballero narró como la fiesta se reemplazó por las ejecuciones en la plaza mayor de Antonio Baraya, destacado militar de la primera república Neogranadina. Caballero inicia el relato del día 20 recordando que es el día de santa Librada y lo concluye así: «iVirgen Santa, A tu

54 Ricardo del Molino García, «Ricaurte es superior a Leónidas, Escévola y Régulo. El uso político de los héroes grecorromanos en la Primera República colombiana», en Estudios Filológicos en honor del profesor Enrique Barajas. Aproximaciones Interdisciplinarias a la antigüedad griega y latina, ed. por Laura Almandós y Ronald Forero (Bogotá: Universidad Nacional de Colombia, Universidad de los Andes y Universidad de La Sabana, 2016), 429, 432. Sobre este tema ver: Abel Martínez y Andrés Otálora, «En átomos volando. Antonio Ricaurte y la Construcción de la Imagen de un Héroe-Mártir (1883-1920)», Americanía 5 (2017): 103-123.

55 Georges Lomné, «Las ciudades de la Nueva Granada: teatro y objeto de los conflictos de la memoria política (18101830)», Anuario Colombiano de Historia Social y de la Cultura n. 21 (1993): 128.

56 Caballero, Particularidades..., 188-190.

57 Jaime de Almeida, «¿200 años de olvido? Santa Librada en la memoria de la Independencia», en Independencia, independencias y espacios culturales. Diálogos de Historia y Literatura, ed. por Carmen Elisa Acosta, Cesar Ayala y Henry Alberto Cruz (Bogotá: Universidad Nacional de Colombia, Asociación de Colombianistas, 2009), 143.

\title{
Estudios Históricos
}


patrocinio me acojo; defiéndenos por tus entrañas de amor!» ${ }^{58}$. Ese mismo año, el Pacificador Morillo celebró solemnemente en la iglesia del convento de Santo Domingo la fiesta en honor a la Virgen de Chiquinquirá, recuperada por los realistas mientras la imagen de santa Librada volvía a la iglesia hospitalaria ${ }^{59}$. Al respecto, y en línea con lo anotado por Caballero, Miramón afirma que una copla popular en la capital durante la ocupación de los expedicionarios reclamaba:

$$
\begin{gathered}
\text { Santa Librada! Santa Librada! } \\
\text { Yo le pedía y ella me daba } \\
\text { una moneda por la semana, } \\
\text { por la semana... }{ }^{60}
\end{gathered}
$$

El autor del aclamado y publicitado discurso en honor a la santa patrona del difícil parto de la Independencia fue juzgado por el tribunal eclesiástico establecido por los expedicionarios, debido a su evidente participación en las ceremonias religiosas de la primera República y en especial las dedicadas a santa Librada. Finalmente, el padre Florido negó dentro del proceso la impresión del sermón, aunque sí admitió haber jurado la independencia ${ }^{61}$.

\section{Fiestas patrias}

Luego del triunfo de Boyacá en 1819, la proclamación de la República de Colombia y la promulgación de la Constitución, la fecha del 20 de julio es tempranamente olvidada, siendo reemplazada por la del 7 de agosto como la del logro de la Independencia. La memoria de santa Librada siguió activa en la República de Colombia. El antiguo convento dominico de Nuestra Señora de las Aguas, que había sido convertido en hospital en 1801 durante la epidemia de viruela, y donde se acuarteló el Batallón de las Milicias de Pardos en 1810, se llamó Hospital Militar de santa Librada después de 181962. Mediante Decreto del 29 de enero de 1823 de Francisco de Paula Santander, se estableció en Cali un colegio republicano que se llamó Santa Librada, ${ }^{63}$ en conmemoración del día en que hizo su revolución la antigua Nueva Granada, el día de santa Librada.

De acuerdo con Sandra Rodríguez, «los festejos patrios se iniciaban regularmente con rituales religiosos que influyeron, de manera decisiva, durante el periodo, en la conformación de una memoria patriótica» ${ }^{64}$. En efecto, en la celebración religiosa del Centenario de

58 Caballero, Particularidades..., 239.

59 Más información sobre Santa Librada y sus ciclos festivos en los siglos xix y xx ver: Jaime de Almeida, «Santa Librada, en las vísperas del Bicentenario», Revista Historia y Espacio, n. 33 (2009).

60 Alberto Miramón, «La poesía patriótica en la época del Terror», Thesaurus Xxi, n. ${ }^{\circ} 2$ (1966): 322.

61 Roger Pita Pico, «El cura Francisco Antonio Florido y su aporte al proceso de Independencia de Colombia: aproximaciones a las facetas de un patriota integral», 'ILu. Revista de Ciencias de las Religiones, n. 22 (2017): 311.

62 Hugo Sotomayor, Guerras, enfermedades y médicos en Colombia (Bogotá: Escuela de Medicina Juan N. Corpas, 1997), 202-203

63 John Lane Young, La Reforma Universitaria de la Nueva Granada (1820-1850) (Bogotá: Universidad Pedagógica Nacional e Instituto Caro y Cuervo, 1994), 48.

64 Sandra Patricia Rodríguez Ávila, Memoria y Olvido: usos públicos del pasado en Colombia, 1930-1960 (Bogotá: Universi-

Ciencia Nueva. Revista de Historia y Política | ISSN 2539-2662 | Vol. 5 Núm. 1 (enero-junio de 2021) DOI: https://doi.org/10.22517/25392662.23521 
la Independencia Nacional, en la que reaparece santa Librada, el canónigo de la catedral de Bogotá Rafael María Carrasquilla afirmó sobre la relación entre patria y religión: «La Iglesia fue la civilizadora de nuestra Nación, la libertadora de nuestra Patria, la fundadora de nuestra República» ${ }^{65}$.

Santa Librada desapareció luego de 1815, reapareció luego de la Independencia en la vicepresidencia de Santander con el Colegio de santa Librada de Cali, volvió a escena durante la presidencia de Santander en la Nueva Granada a partir de 1831 y se efectuaron periódicamente sus procesiones entre 1835 y $1837^{66}$. Durante la presidencia de Pedro Alcántara Herrán, entre 1842 y 1845, se celebró la procesión de santa Librada ${ }^{67}$. En 1849 y 1850, durante la presidencia del liberal José Hilario López, la fiesta del 20 de Julio tuvo entre otras actividades, la procesión nocturna de santa Librada desde la iglesia de Las Nieves hasta la catedral:

La imagen lucía vistosamente adornada entre ángeles, en una mano lleva una corona de laurel y en la otra la banda tricolor; precedida por un carro triunfal ocupado por tres señoritas, en alusión a las tres repúblicas que Bolívar libertó. Santa Librada era la patrona de los artesanos, autores del triunfo liberal y por consiguiente toma sitio de honor al lado del presidente y sus secretarios. La procesión se extendió por cuatro cuadras, en la que participaron miembros de la sociedad de artesanos, alumnos del Colegio Militar, del Espíritu Santo y de la Concordia y un gran número de patriotas [...]. La imagen de la santa se colocó en la gran galería de la casa municipal, se entonaron canciones patrióticas y discursos del coronel Vicente Piñerez y de Emeterio Heredia dirigente de los artesanos, quien resalta tres cosas: la concepción de los próceres como padres de la patria, la relación entre religión y la Independencia y la exhortación a la unidad como tributos a los padres de la patria. ${ }^{68}$

En medio de los conflictos armados del siglo XIX, santa Librada aparece y desaparece de acuerdo con las circunstancias, Rodríguez registra datos dispersos de la procesión en $1855^{69}$, 1866,1867 y $1869^{70}$.

En la presidencia de Manuel Murillo Toro se promulgó la Ley 60 del 8 de mayo de 1873 «Sobre la celebración del aniversario de la Independencia Nacional», en cuyo artículo primero se estipulaba: «Declárase día festivo para la República el 20 de julio, como aniversario de la proclamación de la Independencia nacional en 1810», y en el segundo se destinaba una partida anual de dos mil pesos para la celebración de esta fiesta patriótica ${ }^{71}$. Entre 1870 y 1874 se regularizó la procesión de santa Librada ${ }^{72}$.

dad Nacional de Colombia, Universidad del Rosario, 2017), 111.

65 Alexander Pereira Fernández, «Cachacos y guaches: la plebe en los festejos bogotanos del 20 de julio de 1910», Anuario Colombiano de Historia Social y de la Cultura 38, n. ${ }^{\circ} 1$ (2011): 90.

66 Rodríguez, Memoria y Olvido..., 111

67 Rodríguez, Memoria y Olvido..., 111

68 Oscar Blanco Mejía, «Fiesta y Patria durante la Regeneración en Colombia. Santander (1886-1899)», Historia 2.0 II, No 3 (2012): 44.

69 Rodríguez encuentra en la Biblioteca Luis Ángel Arango (BLAA) un panegírico de Santa Librada, predicado en la Catedral de Bogotá el 20 de julio de 1855 y escrito por Paulino A. Olivos, en el cual nombra a la santa como Wildeforte. Rodríguez, Memoria y Olvido..., 113.

70 Rodríguez, Memoria y Olvido..., 111

71 República de Colombia-Congreso de los Estados Unidos de Colombia. Ley 60 de 1873 (8 de mayo) «Sobre celebración del aniversario de la Independencia Nacional» (Diario Oficial No. 854, Bogotá, 16 de mayo de 1873), 1.

72 Rodríguez, Memoria y Olvido..., 113.

\section{Estudios Históricos}


Durante la «Hegemonía Conservadora» (1886-1930), la santa virgen Librada desaparece de los desfiles por la relación que tuvo con los gremios de artesanos ${ }^{73}$. No obstante, la podemos encontrar en las fiestas patrias del Centenario de la Independencia en 1910, presentándose en cinco ocasiones más hasta $1920^{74}$. Durante los años veinte se realizó la procesión. Por ejemplo, el 20 de julio de 1928, se llevó a cabo un acto típico de las fiestas patrias de la última década de la Hegemonía Conservadora, en el cual se registró una gran participación de los escolares en actos literarios, desfiles, jura a la bandera en la plaza, ofrendas florales y cantos masivos del himno nacional. Para el caso particular de santa Librada su antiguo uso taumatúrgico resurge, se combina con el ejercicio de la beneficencia pública en el marco de la fiesta de la Independencia Nacional:

En el dormitorio de niños pobres de la Cruz Roja de una sala que llevará el nombre de santa Librada, y colocación del retrato de la imagen. La Junta de Festejos obsequiará a los niños vestidos y abrigos, y uno de sus miembros, el doctor Pedro Peña, les manifestará el significado de la fecha que se conmemora ${ }^{75}$.

Entre 1930 y 1934 con el ascenso de los liberales al poder, se hicieron modificaciones en el recorrido de la procesión de santa Librada, incluyendo la iglesia de La Veracruz, panteón nacional de la Independencia en donde se encuentra el Cristo de los Mártires, se desplaza luego al parque de los Mártires ${ }^{76}$, frente a la iglesia del Voto Nacional y la Facultad de Medicina de la Universidad Nacional.

En el primer año de gobierno del general Gustavo Rojas Pinilla, la procesión de santa Librada y del Cristo de los Mártires pasó al 18 de julio porque en la fecha en que tradicionalmente se había realizado se programó un desfile militar en honor al presidente. En 1954 se realizó la procesión el 19 de julio, pero el desfile militar y los honores al general desplazaron los actos religiosos en la agenda de festejos patrios, así como la importancia de sus asistentes ${ }^{77}$.

Santa Librada estará presente en las celebraciones y desfiles hasta 1959 (figura 4). En 1960, Sesquicentenario de la Independencia Nacional, la procesión se convirtió en un desfile de los descendientes de los próceres, el batallón Guardia Presidencial, la Escuela Militar de Cadetes, la Academia Colombiana de Historia, la Sociedad Bolivariana y el Cristo de los Mártires $^{78}$, mientras la santa virgen y mártir Librada, patrona de los partos difíciles y de la Independencia pasaba al Museo Casa del Florero, organizado por la Academia Colombiana de Historia con la participación de Luis Alberto Acuña. El Concilio Vaticano Segundo ${ }^{79}$, re-

\footnotetext{
73 Blanco, «Fiesta y Patria durante la Regeneración en Colombia. Santander (1886-1899)», 51.

74 Rodríguez, Memoria y Olvido..., 113.

75 Marcos González Pérez, Ceremoniales, fiesta y nación. Bogotá: Un escenario (Bogotá: Intercultura Colombia, 2012 ), 325.

76 Rodríguez, Memoria y Olvido..., 117.

77 Rodríguez, Memoria y Olvido..., 125.

78 Rodríguez, Memoria y Olvido..., 133-134.

79 Almeida sostiene que una de las posibles causas de su desaparición es este Concilio. Jaime de Almeida. «Santa Librada, patrona del día 20 de julio, en el Primer Centenario de la Independencia de Colombia», en Actas del XIV Encuentro de Latinoamericanistas Españoles. 200 años de Iberoamérica (1810-2010), ed. por Eduardo Rey Tristán y Patricia Calvo González (Santiago de Compostela: Universidad de Santiago de Compostela, 2010), 386 y Almeida y Gamboa. ¡Santa Libertad!... Ver también: Jaime de Almeida, «Santa Librada y la Academia Colombiana de Historia», Boletín de Historia y Antigüedades n. ${ }^{\circ}$ 858 (2014): 219-242. En 1962, Santa Librada es reemplazada por la Virgen de la Asunción como patrona de la diócesis de Sigüenza. Martínez Gómez-Gordo, «Santa Librada...», 12.
}

Ciencia Nueva. Revista de Historia y Política | ISSN 2539-2662 | Vol. 5 Núm. 1 (enero-junio de 2021) DOI: https://doi.org/10.22517/25392662.23521 
unido en aquellos años, también propicio la desaparición de la virgen mártir, patrona de los partos difíciles, incluido el más difícil de todos, la Independencia.

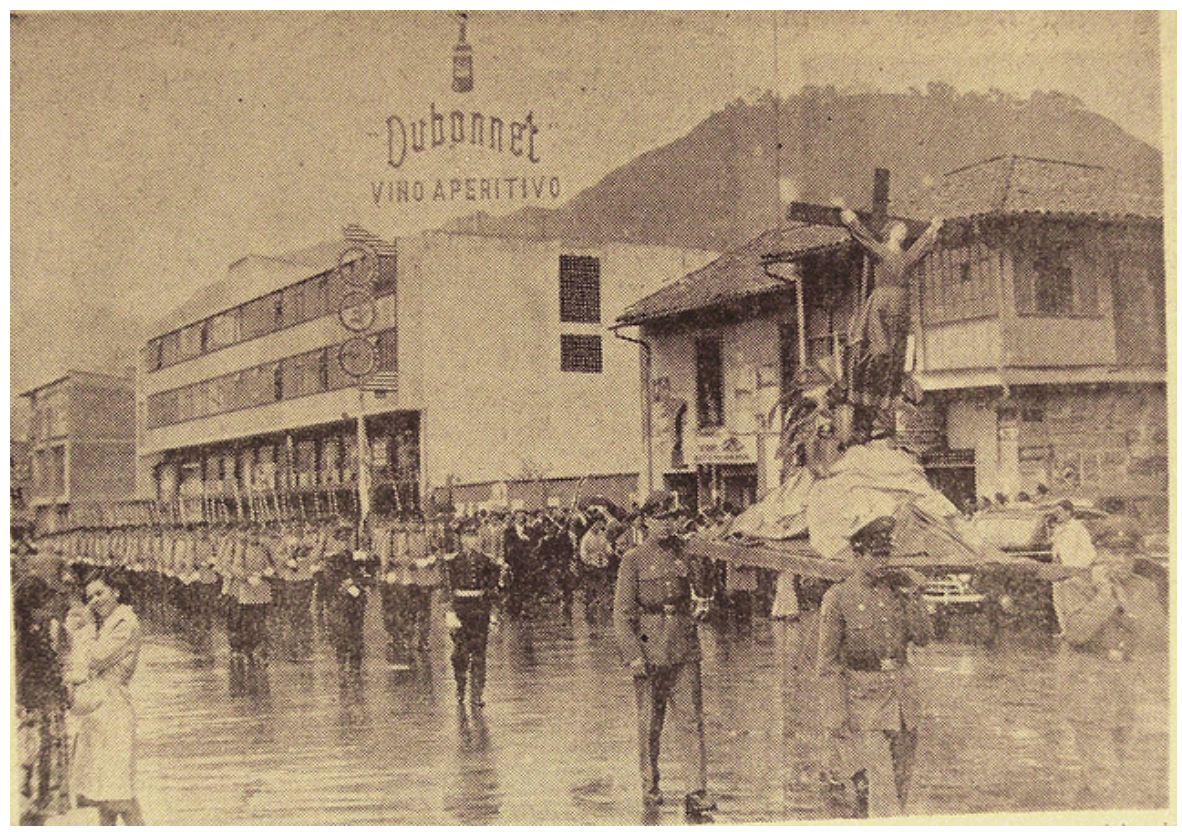

Figura 4. Procesión de santa Librada entrando a la plaza de Bolívar por la carrera $7 .{ }^{\text {a }}$ de Bogotá, julio de 1954 (El Espectador).

Fuente: Marcos González Pérez, La Fiesta en Colombia (Bogotá: Credencial Historia, 2017), 17.

\section{Conclusiones}

El culto paleocristiano de santa Librada tiene una amplia difusión en el norte de la península ibérica y en la región de Aquitania. Su culto está relacionado con el camino de Santiago y con el inicio de la reconquista de la península en Asturias. El traslado de las reliquias de la virgen y mártir a la catedral de Sigüenza oficializan la devoción a la santa, a donde fue llevada por los benedictinos, quienes son la primera orden monástica dedicada de lleno a la atención de los enfermos y de los peregrinos del medieval camino jacobeo. Desde el inicio del culto, las cualidades taumatúrgicas relacionadas con atención de los partos difíciles, por su leyenda, problemas de esterilidad y dificultades en el matrimonio, acompañaron la devoción a la figura de santa Librada.

Durante el Renacimiento y por patrocinio de un canónigo cercano al emperador Carlos V, se construyó en la catedral de Sigüenza un altar-relicario en honor a la virgen mártir. En las pinturas, que contienen escenas de la vida de las hermanas de la santa, se incluye también una alegoría a los trabajos de Hércules, figura mitológica que paso a ser uno de los símbolos asociados a la monarquía de los Austrias, y en especial del emperador.

\section{Estudios Históricos}


El paso de su imagen y culto a América se debe a Diego Ladrón de Guevara (16411718) nombrado obispo de Panamá, ciudad a la que llegó en 1693. Ladrón de Guevara había sido canónigo en Sigüenza de donde trasplanta la devoción, ya que solicita a Sigüenza una reliquia para honrar a la santa en la catedral de la ciudad de Panamá que se encontraba en construcción. El obispo Ladrón de Guevara tuvo un importante recorrido por varias diócesis y provincias americanas por donde dispersó el culto a santa Librada. En Quito, una escultura permanece aún en la iglesia del convento de La Concepción en la esquina de la Plaza Grande como recuerdo del paso del obispo-virrey. En Lima, la iglesia de santa Liberata, queda como testigo del paso de Ladrón de Guevara, quien además fue un gran promotor de la orden hospitalaria americana de los betlemitas. En Panamá se sigue celebrando, en la villa de Las Tablas, a la santa virgen Librada, y en 2006, el obispo de Sigüenza donó una reliquia de la santa virgen y mártir.

La introducción y difusión de su devoción en Nueva Granada se relaciona con la inauguración de un nuevo convento hospital de la orden de San Juan de Dios en Santafé en 1723, a donde llega una imagen quiteña de la santa crucificada, la cual se puso en uno de los altares laterales de la nueva iglesia del hospital, en donde conservó las cualidades taumatúrgicas como intercesora de las mujeres en los partos difíciles, problemas en el matrimonio y contra la esterilidad.

En el marco de las fiestas de santa Librada en honor a la Independencia de la primera república neogranadina, se recurre a esta protomártir de la iglesia por la azarosa coincidencia de la celebración de su fiesta el mismo día de la proclamación de la Junta en Santafé y por el evidente parecido fonético de su nombre Librada (Liberara) con la Libertad (Independencia), haciendo similares en el discurso, las características de la leyenda medieval de santa Librada con el advenimiento de la nueva República. Durante el siglo xIx y xx, santa Librada retornará esporádicamente a su lugar en las procesiones y en la memoria patria del 20 de julio, como fiesta de la Independencia Nacional.

Con la aparición de los protomártires de Colombia a partir de 1815, la Nueva Granada adquiere unos mártires propios, Antonio Ricaurte y Atanasio Girardot, galería de mártires que la reconquista del Ejército Expedicionario de Costa Firme engrosaría. Las características y la representación del primer acto en honor al héroe Antonio Ricaurte, un año después de su sacrificio en la hacienda de San Mateo, revela los significados y semejanzas entre dos jóvenes mártires sacrificados por la causa de la Libertad (Librada y Ricaurte). Lo que empezaría a ocurrir con la imagen de Antonio Ricaurte a partir de allí, no hace sino confirmar las similitudes entre estas dos historias construidas en el inicio de la República.

La memoria de los héroes militares triunfantes reemplaza a la del rey y enmascara las figuras de los primeros mártires como Ricaurte y de los santos asociados a la Independencia como Librada. Unos y otros aparecerán a lo largo de la historia republicana del país durante dos siglos, de acuerdo con la instrumentalización de la memoria política que requiera el régimen gobernante en el momento.

El culto a santa Librada continúa en el siglo xix. Mientras en la Nueva Granada es 
vista como un símbolo de la Independencia, en la España de la restauración absolutista, Fernando viI y su tercera esposa peregrinaron a Sigüenza para que la santa les concediera el anhelado heredero de la corona, la santa mantenía sus cualidades taumatúrgicas como intercesora de las mujeres estériles, con problemas matrimoniales y para el buen parto. En 1962, la santa patrona de la antigua diócesis de Sigüenza, ahora Sigüenza-Guadalajara, es reemplazada por la Virgen de la Asunción, dentro de los cambios en el santoral realizados por el Concilio Vaticano Segundo, misma época en que desaparece su culto republicano en Colombia.

Hoy la imagen de santa Librada se encuentra desacralizada en la Casa del Florero como simbólica pieza del Museo de la Independencia. Su relación antigua con las mujeres que daban a luz o esperaban ser madres, su relación con el convento-hospital de San Juan de Dios y la llegada de este culto a Santafé en el siglo XVIII son temas aun por explorar.

\section{Referencias}

\section{Fuentes primarias}

Anónimo. Novena a la gloriosa virgen y mártir Santa Librada o Wilge-Forte, abogada de quitar los pensamientos tristes, y afligidos. Patrona de la Santa Catedral de la ciudad de Sigüenza, y su Obispado. Córdoba: en la oficina de Don Juan Rodríguez de la Torre, Calle de la Librería, 1785.

Caballero, José Maria. Particularidades de Santafé. Bogotá: Biblioteca Popular de Cultura Colombiana, publicaciones del Ministerio de Educación de Colombia, 1946.

De Nursia, Benito. Regla de nuestro padre San Benito. Madrid: Biblioteca de Autores Cristianos, 2000.

De Peralta Barnuevo y Rocha, Pedro. Imagen política del gobierno del Excmo Señor [sic] D. Diego Ladrón de Guevara, Obispo de Quito, Virrey ... de los Reynos del Perú, Tierra firme y Chile. Lima: por Jerónimo de Contreras, 1714.

Díaz Cayuelas, Joseph. Breve resumen de las glorias de la Virgen y Mártir Santa Librada, patrona de la Santa Iglesia Catedral de Sigüenza y su obispado con el modo de hacer su Novena, para alcanzar del Señor, por intersección de la Santa, las gracias que se desean. Murcia: Por Joseph Díaz Cayuelas, impresor de la ciudad, en frente de San Francisco, 1732.

Florido, Francisco. Sermón que en la fiesta de Santa Librada hecha en obsequio del Excmo. Señor Presidente Don Antonio Nariño por el ilustre cabildo de la villa de Bogotá, pronunció el padre Franciscano Florido de la Orden de San Francisco, el día 3 de enero de 1812. Villa de Bogotá: Imprenta de D. Bruno Espinosa, 1812.

\section{Estudios Históricos}


Real Academia de la Historia (RAH), Madrid: Signatura 9/7649 legajo 6 c) 1, folio 191-200

República de Colombia-Congreso de los Estados Unidos de Colombia. Ley 60 de 1873 (8 de mayo) «Sobre celebración del aniversario de la Independencia Nacional». Diario Oficial n. ${ }^{\circ} 854$, Bogotá, 16 de mayo de 1873.

\section{Fuentes secundarias}

Blanco Mejía, Oscar. «Fiesta y Patria durante la Regeneración en Colombia. Santander (18861899)». História 2.0 II, n. 3 (2012): 37-56.

Carrascal Corbera Eulàlia. «Apologia de l'anorèxia i la bulímia. Treball d’investigació sobre la cara més desconeguda d’una patología endémica». Tesis de Grado en Periodismo. Universidad Autónoma de Barcelona, 2018.

Contreras, Adrián. «In Ligno Facta. Artes escultóricas de los siglos XVII y XVIII en Colombia». Tesis doctoral. Universidad de Granada, Doctorado en Historia y Artes, Departamento de Historia del Arte, 2017.

De Almeida, Jaime. « 200 años de olvido? Santa Librada en la memoria de la Independencia». En Independencia, independencias y espacios culturales. Diálogos de Historia y Literatura, editado por Carmen Elisa Acosta, Cesar Ayala y Henry Alberto Cruz, 139-162. Bogotá: Universidad Nacional de Colombia, Asociación de Colombianistas, 2009.

. «Santa Librada, en las vísperas del Bicentenario». Revista Historia y Espacio, n. 33 (2009).

- «Santa Librada, patrona del día 20 de julio, en el primer centenario de la Independencia de Colombia». En Actas del XIV Encuentro de Latinoamericanistas Españoles. 200 años de Iberoamérica (1810-2010), editado por Eduardo Rey Tristán y Patricia Calvo González, 382-395. Santiago de Compostela: Universidad de Santiago de Compostela, 2010.

«Um lugar de memória e de esquecimento: Santa Librada, padroeira da Independência da Colômbia». Revista Brasileira de História 3, n. ${ }^{\circ} 61$ (2011): 41-61.

. «Santa Librada y la Academia Colombiana de Historia». Boletín de Historia y Antigüedades n. 858 (2014): 219-242.

De Almeida, Jaime y William Gamboa. ¡Santa Libertad! Memoria y olvido de una imagen femenina de la Independencia. Bogotá: Ministerio de Cultura, Museo de la Independencia-Casa del Florero, Sociedad de Mejoras y Ornato de Bogotá, 2009.

Del Molino García, Ricardo. «Ricaurte es superior a Leónidas, Escévola y Régulo. El uso po- 
Abel Fernando Martínez Martín Andrés Ricardo Otalora Cascante

lítico de los héroes grecorromanos en la Primera República colombiana». En Estudios Filológicos en honor del profesor Enrique Barajas. Aproximaciones Interdisciplinarias a la antigüedad griega y latina, editado por Laura Almandós y Ronald Forero, 419-438. Bogotá: Universidad Nacional de Colombia, Universidad de los Andes y Universidad de La Sabana, 2016.

Díaz Tena, María Eugenia. «La vida de Santa Librada y su fuente medieval». Culturas Populares n. 8 (2009): 1-22.

Estebaranz, Ángel Justo. «Las donaciones a España del obispo de Quito don Diego Ladrón de Guevara». Artigrama n. ${ }^{\circ} 24$ (2009): 225-234.

Fernández García, Joaquín, Rodrigo Fernández Alonso y José Martínez González. «Oraciones para la salud humana y animal en la poesía popular asturiana». En Actes del II Conceyu Internacional de Lliteratura Asturiana, editado por Academia de la Llingua Asturiana, 105-160. Oviedo: Academia de la Llingua Asturiana, 2007.

Gélis, Jacques. «Le cuite de Santa Librada a Sigüenza: Patronage urbain et emblématique impériale». Revista de Dialectología y Tradiciones Populares 51, n. ${ }^{\circ} 1$ (1996): 221-239.

«Reliquias y cuerpos miraculados». En Historia del Cuerpo vol. I., coordinado por Alain Corbin, Jean Jacques Courtine y Georges Vigarello, 83-104. Madrid: Taurus, 2005.

Gentile, Margarita E. "Ciento nueve años después de "La Cruz en América”». En Los crucificados, religiosidad, cofradías y arte, editado por Francisco Javier Campos y Fernández de Sevilla, 997-1014. San Lorenzo del Escorial: Real Centro Universitario Escorial-María Cristina, 2010.

González Pérez, Marcos. Ceremoniales, fiesta y nación. Bogotá: Un escenario. Bogotá: Intercultura Colombia, 2012.

La Fiesta en Colombia. Bogotá: Credencial Historia, 2017.

Lomné, Georges. «Las ciudades de la Nueva Granada: teatro y objeto de los conflictos de la memoria política (1810-1830)». Anuario Colombiano de Historia Social y de la Cultura n. 21 (1993): 114-135.

López Herrero, Luis-Salvador. «Anorexia: comer nada. Una perspectiva psicoanalítica». Revista de la Asociación Española de Neuropsiquiatría XIX, n. ${ }^{\circ} 72$ (1999): 599-608.

Martínez Garnica, Armando. «La reasunción de la soberanía por las juntas de notables en el Nuevo Reino de Granada». En 1808: la eclosión juntera en el mundo hispano, coordinado por Manuel Chust, 286-333. México: Fondo de Cultura Económica, El Colegio de México, 2007.

\section{Estudios Históricos}


Santa Librada, de los partos difíciles a la

independencia de Cundinamarca

Martínez Gómez-Gordo, Juan A. «Santa Librada, virgen y mártir (revisión de su hagiografía, iconografía y culto)». Anales Seguntinos n. ${ }^{\circ} 12$ (1996): 7-89.

Martínez Martín, Abel y Andrés Otálora. «En átomos volando. Antonio Ricaurte y la construcción de la imagen de un héroe-mártir (1883-1920)». Americanía 5 (2017): 103123.

Miramón, Alberto. «La poesía patriótica en la época del Terror». Thesaurus Xxi, n. 2 (1966): 301-330.

Moreno Egas, Jorge y Nancy Morán Proaño. Historia del antiguo Hospital San Juan de Dios Tomo I. Quito: Museo de la Ciudad, 2012.

Nieto Jiménez, Marcos. Santa Librada. Lo que se esconde detrás. Guadalajara (España): Aventura Gráfica, 2017.

Ocampo López, Javier. El proceso ideológico de la emancipación en Colombia. Bogotá: Planeta, 1999.

Pereira Fernández, Alexander. «Cachacos y guaches: la plebe en los festejos bogotanos del 20 de julio de 1910». Anuario Colombiano de Historia Social y de la Cultura 38, n. ${ }^{\circ} 1$ (2011): 79-108.

Pita Pico, Roger. «El cura Francisco Antonio Florido y su aporte al proceso de Independencia de Colombia: aproximaciones a las facetas de un patriota integral». 'ILu. Revista de Ciencias de las Religiones 22 (2017): 301-322.

Rodríguez Ávila, Sandra Patrícia. Memoria y Olvido: usos públicos del pasado en Colombia, 1930-1960. Bogotá: Universidad Nacional de Colombia, Universidad del Rosario, 2017.

Sanz Hermida, Jacobo. "Una vieja barbuda que se dice Celestina”: Notas acerca de la primera caracterización de Celestina». Celestinesca 18 (1994): 17-33.

Sotomayor, Hugo. Guerras, enfermedades y médicos en Colombia. Bogotá: Escuela de Medicina Juan N. Corpas, 1997.

Spranger, Peter. Der Geiger von Gmünd: Justinus Kerner und die Geschichte einer Legende. Heidelberg: Stadtarchiv, 1991.

Vallín Rodolfo y Vargas Murcia Laura. Iglesia de San Juan de Dios. Bogotá: Arquidiócesis de Bogotá, 2004.

Vargas, José María. Historia de la Iglesia en el Ecuador durante el patronato español. Quito: Editorial Santo Domingo, 1962. 
Young, John Lane. La Reforma Universitaria de la Nueva Granada (1820-1850). Bogotá: Universidad Pedagógica Nacional e Instituto Caro y Cuervo, 1994.

Zawadzky, Alfonso. «Fr. Francisco Antonio Florido». Repertorio Boyacense 7, n. 75 (1925): 85-90. 